\title{
Information Needs and Modalities among People Affected by the Fukushima Nuclear Disaster
}

\author{
Akiko Sato \\ Institute for the Advanced Study of Sustainability, United Nations University, Japan
}

Copyright $\subseteq 2017$ by authors, all rights reserved. Authors agree that this article remains permanently open access under the terms of the Creative Commons Attribution License 4.0 International License

\begin{abstract}
Timely communication of accurate and practical information is indispensable for nuclear disaster management. This study aimed to collect lessons from the 2011 Fukushima nuclear disaster by analyzing people's information needs, as well as their sources and channels of information since the disaster. This study also explored common challenges they faced in information seeking, and information disparities among them. One-to-one interviews and focus group discussions were conducted in June-September 2015 with key stakeholders, involving affected residents, civil society organizations, municipal government officials and social workers in Fukushima prefecture. This study revealed that information needs immediately after the disaster directly related to their survival and the safety assurance of families and others. But information needs became diverse, reflecting a wide range of impacts of the nuclear disaster. The communication modalities on which participants relied for obtaining information varied by individual. But people experienced various difficulties in gaining information due to the chaotic circumstances during and after the disaster, the long-lasting and complicated disaster recovery process, different perceptions of radiation risks and public distrust of government bodies and Tokyo Electric Power Company. There were information disparities between affected people living in temporary housing units for evacuees and those living elsewhere. The findings indicate that risk factors for poor information access and utilization also included living in an elderly-only household, having limited social interactions, and living outside Fukushima prefecture. Study participants raised concerns that the information disparities would likely increase under the current Japanese government policy of accelerating disaster-recovery operations.
\end{abstract}

Keywords Nuclear Disaster, Fukushima, Information Needs, Information Modality, Information Disparity, Vulnerability, Radiation, Risk Perception

\section{Introduction}

A nuclear power plant accident can cause both disruptions to facility operations and major threats to environmental and human safety [1]. In March 2011, Japan suffered a major nuclear accident following the Great East Japan Earthquake and tsunami (hereafter, the 3.11 disasters). Consequently, a large amount of radionuclides, including iodine-131, caesium-134 and caesium-137 were released from Fukushima Daiichi Nuclear Power Plant (FDNPP) of Tokyo Electric Power Company (TEPCO) into the surrounding environment. The half-life of iodine-131 is 8 days. However, the half-lives of caesium-134 and caesium-137 are 2 years and 30 years, respectively, which has led to long-term public health concerns [2]. In the case of Fukushima, together with the immense impacts from the enormous earthquake and tsunami, the scale of the nuclear accident and the composition of released radionuclides have resulted in serious environmental contamination and large-scale human displacement $[2,3]$.

Prompt provision of accurate information concerning a nuclear disaster situation is vital for an optimal response [4]. When the Fukushima disaster occurred, however, information about the accident at FDNPP and the need to evacuate were not swiftly conveyed to all concerned municipal governments and residents. The speed of information dissemination by the Government of Japan was primarily based on the distance from the plant, starting with the area situated within 2-3 km from FDNPP on the evening of March 11 [5]. It was, however, not until April 22 that Iitate village, which is almost entirely outside the $30-\mathrm{km}$ radius from the plant, was designated as a "deliberate evacuation area" and its residents requested by the national government to leave. This delay in providing guidance contributed to chaotic evacuations. In some cases, it resulted in avoidable exposure to ionizing radiation [6,7]. Problems were also reported concerning the administration of stable iodine tablets, which was due to various reasons, such as a dysfunctional government command system, a lack of precise radiation data and people's varying and changing 
situations, which complicated the administration $[8,9]$.

Since the disaster, Japan has devoted tremendous resources to decontamination and rebuilding of infrastructure [10]. Along with the progress of environmental remediation, some municipalities have been reopened. The number of evacuees has almost halved to 83,000 as of November 2016, compared to its peak of 164,865 in May 2012 [3,11]. Nevertheless, there is a salient tendency of a low rate of return and a significant number of "voluntary" evacuees, including those from reopened municipalities or those from outside the evacuation zone, although precise data are not available due to the lack of a national definition of the term and issues with data gathering $[12,13]$. A survey of municipalities in Fukushima prefecture, conducted by a Japanese newspaper publishing company, suggests that as of January 2016, there were approximately 16,000 voluntary evacuees from the nuclear disaster [14]. The eastern part of Miyakoji district in Tamura city was the first area reopened after the disaster; after its termination of the evacuation order in April 2014, over 60\% of residents had returned by February 2016 [15]. However, the return rate of Naraha town, which was reopened in September 2015, was only $9 \%$ as of October 2016 [16]. According to a 2013-2016 Fukushima government survey of evacuees, $41-85 \%$ of evacuees (depending on the municipality) stated that they would not return or were still unable to make a decision [3]. In contrast to the local situation, the national government announced in June 2015 that it would speed up disaster recovery operations with the aim of terminating the evacuation zoning by March 2017, with a gradual discontinuation of compensation payments, except for the "difficult-to-return" areas where annual doses were predicted to continue exceeding 20 millisieverts and access is not permitted at present [17]. The government has planned to reopen some parts of these "difficult-to-return" areas by 2021, while much remains to be resolved [18].

Information communication and decision support systems are important both for the immediate response to a disaster, and for a coordinated and sustainable recovery. A critical prerequisite for effective information communication is ensuring the availability of credible context-specific information. However, a shortage of critical information has been reported not only during the initial response but also in subsequent operations related to the disaster. Factors which have made communication for the management of nuclear disasters challenging are often linked to the health risks of ionizing radiation, as well as the complex and long-term impacts of such disasters on people and society $[19,20]$. In addition, the situations of people affected by the Fukushima nuclear disaster are constantly changing [21], which can greatly influence information needs and the environment for people to seek information.

In addition to the diverse direct consequences of the nuclear disaster, a prior study raises concerns about inequities between people affected by the 3.11 disasters in terms of information access, based on geographical areas and socio-economic status [22]. They note that older generations and rural residents tend to have less information opportunities than their younger and urban counterparts, respectively. Also, there may be a gender difference in information access. Some studies find that among those affected by the nuclear disaster, mothers tend to worry more about current and future radiation impacts, particularly on their children, compared to their spouses - partly because of women's traditional gender roles, taking most, if not all, of the responsibility for childcare and housekeeping $[23,24]$. In Japan's deeply-rooted patriarchal society, the gender difference in risk perception may socially marginalize women with high levels of concern over radiation and hold them back from looking for information that could address their concerns.

Taken together, it is evident that these issues related to information communication greatly hampered effective response actions in the aftermath of the Fukushima nuclear disaster, and they continue to hinder the recovery process. The government's plan to terminate evacuation zoning and financial assistance in the coming years has put further pressure on many evacuees and other affected individuals, creating an increased need for information so that they can decide whether or not to return, and about overall livelihood reconstruction. In addition, Japan is now entering a critical period for reviewing this experience and enhancing its disaster-management capacity and resilience. This study, therefore, aimed to thoroughly explore the affected people's perspectives before they are forgotten or fade away, and build an in-depth understanding of (1) the information they needed immediately after the disaster and how they tried to obtain this information, and (2) their current concerns and information needs, and the mediums people usually use to find this information. The study also intended to explore common challenges experienced by affected people with regard to information seeking, as well as information disparities among them, together with contributing factors for these disparities.

The ultimate goal of this study was to document lessons concerning communication for disaster management in the context of a nuclear disaster, not only in Japan and but also for other countries, especially for those with nuclear industries. Given climate change, technological advances and global population growth, it is likely that such disasters - whether independent or triggered by other hazardous events such as natural disasters - will occur more frequently, and increase in their significance and severity [25-27]. Hence, it is essential to learn from the Fukushima case in order to better prepare for, respond to and recover from future disasters.

\section{Conceptual Model and Perspectives}

This study refers to the Crisis and Emergency Risk Communication (CERC) model discussed by Reynolds and Seeger [28] on the nature and characteristics of public communication during and after unexpected extreme events. 
It also draws upon past studies related to risk perception to identify emotional factors that can influence people's beliefs and attitudes toward hazards and their potential or existing outcomes, especially people's general perceptions about nuclear accidents.

The CERC model considers that in an unforeseen situation communications are developed to swiftly deliver event-oriented information to as much of the key audience (e.g. victims, potential victims and emergency responders) as possible using available mediums, in order to inform them about the current status and probabilistic forecasts of the identified hazard. The model explains that crisis communications are often spontaneous and unstructured, while post-crisis communications tend to be more continuous and systematic, focused on updating knowledge about a specific hazard and improving relevant risk control systems and strategies. This study employed the CERC model to understand possible shifts in the focus and nature of communications throughout the post-disaster period.

The way in which people approach threats can be closely grounded in how they feel, assess and comprehend the possibility of the occurrence and the potential magnitude of adverse impacts on themselves, as well as on their family, property or society. Prior studies have found various psychometric characteristics which can largely influence risk perception. Key psychometric characteristics of hazards include (1) voluntariness, (2) institutional control, (3) catastrophe, (4) fatality, (5) benefit, (6) familiarity, (7) observability, and (8) effect on descendants [29-31]. Importantly, Slovic has found that a nuclear accident tends to be considered as a particularly imposed, uncontrollable, catastrophic, dreadful, unfamiliar and intergenerational risk, compared to other hazards [29]. These psychometric characteristics provoke people's general fear of radiation from a nuclear accident. This study took into account these emotional aspects of radiation risks.

\section{Methods}

This study conducted semi-structured interviews in Fukushima prefecture in June-September 2015. Study participants were evacuees, returnees, local government officials, civil society organization (CSO) representatives, and social workers from municipalities which contain areas where evacuation orders had been or were issued, with the criteria of an expected annual dose exceeding 20 millisieverts in the first year after the disaster and within 20 $\mathrm{km}$ distance from FDNPP [32]. Residents in neighboring non-evacuation areas were also interviewed.

Participants were from Futaba town, Kawauchi village, Namie town, Naraha town, Ōkuma town and Tomioka town in the evacuation zone. Participants from Naraha town were interviewed about one month before the evacuation order to the town was lifted on September 5, 2015.

Some were from Date city, Iwaki city, Kōriyama city, or Tamura city (but not Miyakoji district, part of which was included in the evacuation zone until March 31, 2014) from non-evacuation areas. Although not included in the evacuation zone, Date city, Iwaki city and Kōriyama city contain sectors where the average air dose rate has exceeded 0.23 microsievert per hour, which is considered equivalent to 1 millisievert per year. Decontamination has been carried out in such sectors by each municipality $[33,34]$. In addition, Date city included some sectors where annual doses exceeded 20 millisieverts. These sectors were designated as radiation hotspots until the end of 2012, and residents were encouraged to evacuate temporarily [35,36].

Qualitative data analyzed in the study were collected through 22 individual one-to-one interviews and two focus group discussions. Focus group discussion was applied in the interviews with CSO representatives from Futaba town, Kawauchi village, Namie town and Tomioka town, as well as evacuees from Namie town, because of their limited availability and the advantage of this research method in collecting a range of views and large amount of information in a relatively naturalistic, non-judgmental manner within a short period of time [37]. Returnees and those who had never evacuated were interviewed at their homes, workplaces or public facilities in their respective municipalities, except for one non-evacuee who was interviewed by telephone at his request. The others were interviewed in the lounge areas of temporary housing sites for evacuees, public facilities or their workplaces in the municipalities to which they had evacuated. The focus group session with CSO representatives was held in Kōriyama city, and the one with evacuees from Namie town was held in Fukushima city where their community center was situated. Informed consent was obtained from all participants.

This study employed a non-probability convenience sampling method. The data collection was conducted with support from local CSOs and individual partners who are providing support for evacuees and returnees, as well as one CSO based in Tokyo, which advocates citizen science and promotes a participatory approach in monitoring and sharing radiation data. Participants were invited through their networks, and the individual networks of several study participants and the author.

Interview questions were composed of a series of open-ended questions, soliciting narratives regarding participants' experiences and perspectives. The conversations were recorded with an audio recorder, except for the participant interviewed by telephone and three individual-interview participants due to requests from partners who liaised between the participants and the author. The average duration of the one-to-one interviews was approximately 60 minutes, whereas the focus group discussions took 120-150 minutes per group. Field notes were taken concurrently by the author during all of the interviews to supplement the recorded verbal data. In the focus group discussions with CSO representatives, sticky notes were used to facilitate the conversation and arrange comments by the municipalities which they were supporting. 
Qualitative data were transcribed. After reviewing all of the transcripts line by line, key topics were coded throughout the transcripts with the identification of substantial remarks from the participants. The coded data were, then, clustered to identify key themes. Through the coding process, the author developed an overall sense of the data, the key themes and the interconnections between these themes.

Data from the study were not quantified because of the small sample size, especially for several selected municipalities, as well as the different data collection methods applied in the study and the varying backgrounds of the participants. This paper outlines the main perspectives on specific themes and subcategories that frequently emerged in the study among participants, ordered by the chronology of the disaster: (1) during and immediately after the disaster, (2) during evacuation, and (3) at present, specifically in the year 2015 when this study was conducted. Finally, this paper presents the participants' views on information disparities among affected people.

\section{Results}

\subsection{Study Participants}

A total of 39 people, of a broad range of ages, participated in the individual interviews or focus group discussions. Table 1 summarizes the distribution of participants by their place of origin or support, as well as their background. There were 21 men and 18 women. All participants, except for two CSO representatives and three municipal government officials including two public health nurses, were evacuees from their respective municipalities. These two CSO representatives and three government officials were from other municipalities that had also been included in the official evacuation zone. The residence of the participant from Date city was not a part of a radiation hotspot in the city. The participant from Tamura city was not from Miyakoji district in the city.

The three returnees from Kawauchi went back to the village either when the mayor reopened the village in April 2012 (except for the area within a $20-\mathrm{km}$ radius from FDNPP), or when temporary housing for evacuees in the village opened in June 2012. One participant from Kōriyama city and the participant from Iwaki city evacuated during the first few days of the disaster, but returned home after one month and one week, respectively. Of the participants from outside the evacuation zone, only one person was still displaced when the interview was conducted. Of the study participants, three people (two evacuees and one returnee) reported that they had children of pre-school age when the disaster occurred. No participants were pregnant, or had pregnant spouses or infants at that time.

Table 2 lists study participants' main concerns and information needs, as well as communication modalities, together with major challenges in each phase since the nuclear disaster.

\subsection{During and Immediately after the Disaster}

\section{Main Concerns and Information Needs}

When the disaster took place, all evacuees and returnees, regardless of whether they were from the evacuation zone or not, commented that they attempted to understand the situation of FDNPP, such as what had happened, how serious the accident was, and whether the accident was still ongoing. Some participants, especially those who lived in a coastal area that had been severely affected by the Great East Japan Earthquake and tsunami, emphasized that they also needed to be promptly updated about aftershocks and tsunami. Likewise, people looked for information about whether and to where they should evacuate, and desperately tried to confirm the safety of family members, friends and others.

Table 1. Backgrounds of study participants

\begin{tabular}{|c|c|c|c|c|c|c|c|c|}
\hline \multirow[b]{2}{*}{ Municipality } & \multicolumn{3}{|c|}{ Citizens } & \multirow[b]{2}{*}{ CSOs } & \multicolumn{2}{|c|}{ Local government officials } & \multirow[b]{2}{*}{ Social workers } & \multirow[b]{2}{*}{ TOTAL (\#) } \\
\hline & Evacuees & Returnees & $\begin{array}{c}\text { Never } \\
\text { evacuated }\end{array}$ & & $\begin{array}{l}\text { Public health } \\
\text { nurses }\end{array}$ & Other & & \\
\hline Futaba & 0 & 0 & 0 & 0 & 0 & 0 & 3 & 3 \\
\hline Kawauchi & 0 & 3 & 0 & 2 & 0 & 1 & 0 & 6 \\
\hline Namie & 10 & 0 & 0 & 2 & 0 & 0 & 0 & 12 \\
\hline Naraha & 0 & 0 & 0 & 2 & 2 & 1 & 3 & 8 \\
\hline Ōkuma & 2 & 0 & 0 & 0 & 0 & 0 & 0 & 2 \\
\hline Tomioka & 0 & 0 & 0 & 3 & 0 & 0 & 0 & 3 \\
\hline Date & 0 & 0 & 1 & 0 & 0 & 0 & 0 & 1 \\
\hline Iwaki & 0 & 1 & 0 & 0 & 0 & 0 & 0 & 1 \\
\hline Kōriyama & 0 & 1 & 1 & 0 & 0 & 0 & 0 & 2 \\
\hline Tamura & 1 & 0 & 0 & 0 & 0 & 0 & 0 & 1 \\
\hline TOTAL (\#) & 13 & 5 & 2 & 9 & 2 & 2 & 6 & 39 \\
\hline
\end{tabular}


Table 2. Summary of study participants' main concerns, information needs, communication modalities and common challenges in information seeking since the Fukushima nuclear disaster

\begin{tabular}{|c|c|c|c|c|}
\hline & & $\begin{array}{l}\text { During and immediately } \\
\text { after the disaster }\end{array}$ & During evacuation & At present \\
\hline \multirow{6}{*}{$\begin{array}{l}\text { Main concerns \& } \\
\text { information } \\
\text { needs }\end{array}$} & Radiation & $\begin{array}{l}\text { - The occurrence and } \\
\text { magnitude of the } \\
\text { accident at FDNPP }\end{array}$ & $\begin{array}{ll}- & \text { The situation of FDNPP } \\
\text { - } & \text { Basic information about } \\
\text { radiation } \\
\text { - } \\
\text { Radiation exposure levels, } \\
\text { associated health risks }\end{array}$ & $\begin{array}{ll}\text { - } & \text { Decommissioning at FDNPP } \\
\text { - } & \text { Decontamination } \\
& \text { Radiation exposure in } \\
& \text { everyday life }\end{array}$ \\
\hline & $\begin{array}{l}\text { Health of } \\
\text { oneself, } \\
\text { family and } \\
\text { others }\end{array}$ & $\begin{array}{l}\text { - } \\
\text { - } \\
\text { - }\end{array}$ & $\begin{array}{l}\text { - Management of chronic } \\
\text { diseases }\end{array}$ & $\begin{array}{l}\text { Social welfare services and } \\
\text { elderly care }\end{array}$ \\
\hline & $\begin{array}{l}\text { Financial } \\
\text { issues }\end{array}$ & & $\begin{array}{l}\text { - Compensation and other } \\
\text { assistance from TEPCO and } \\
\text { the government }\end{array}$ & $\begin{array}{l}\text { - } \quad \text { Compensation payments, the } \\
\text { progress of ADR } \\
\text { - } \quad \text { Employment opportunities }\end{array}$ \\
\hline & $\begin{array}{l}\text { Life in } \\
\text { evacuation }\end{array}$ & $\begin{array}{l}\text { - The location of } \\
\text { emergency shelters }\end{array}$ & $\begin{array}{ll}- & \text { Relief supplies } \\
\text { - Access to shops to buy daily } \\
\text { necessities and medical } \\
\text { facilities, schools for } \\
\text { children } \\
\end{array}$ & $\begin{array}{l}\text { Integration in the place of } \\
\text { evacuation }\end{array}$ \\
\hline & $\begin{array}{l}\text { Situation of } \\
\text { the place of } \\
\text { origin }\end{array}$ & & $\begin{array}{l}\text { The safety of the } \\
\text { municipality of origin, the } \\
\text { possibility to return home } \\
\text { The restoration of lifeline } \\
\text { infrastructure (evacuees } \\
\text { from non-evacuation areas) }\end{array}$ & $\begin{array}{l}\text { - } \\
\text { The status of infrastructure } \\
\text { reconstruction } \\
\text { Hometown's vision for the } \\
\text { future } \\
\text { - } \quad \text { Rebuilding of community ties } \\
\text { Neighborhood safety }\end{array}$ \\
\hline & $\begin{array}{l}\text { Housing and } \\
\text { property }\end{array}$ & & $\begin{array}{l}\text { - Temporary housing for } \\
\text { evacuees }\end{array}$ & $\begin{array}{l}\text { Compensation and finding } \\
\text { available carpenters } \\
\text { Moving out of temporary } \\
\text { housing }\end{array}$ \\
\hline \multirow[t]{2}{*}{$\begin{array}{l}\text { Communication } \\
\text { modalities }\end{array}$} & $\begin{array}{l}\text { Mandatory } \\
\text { evacuees }\end{array}$ & $\begin{array}{l}\text { Municipal emergency } \\
\text { alerts, emergency } \\
\text { responders } \\
\text { Family and } \\
\text { community members }\end{array}$ & $\begin{array}{ll}\text { - } & \text { Television, radio, } \\
& \text { newspapers } \\
\text { - } & \text { Family and community } \\
& \text { members, friends } \\
\text { - } & \text { Local people, noticeboards } \\
& \text { at evacuation sites } \\
\text { - } & \text { People and publications } \\
& \text { from municipal governments } \\
& \text { and TEPCO } \\
\text { - } & \text { Tablet computers provided } \\
& \text { by municipal governments } \\
\text { - } & \text { Experts }\end{array}$ & $\begin{array}{ll}\text { - } & \text { Television, radio, newspaper, } \\
\text { internet } \\
\text { - } \\
\text { Family and community } \\
\text { members, friends } \\
\text { - } \quad \text { People and publications from } \\
\text { municipal governments and } \\
\text { TEPCO } \\
\text { Tablet computers provided by } \\
\text { municipal governments } \\
\text { - } \quad \text { Experts } \\
\text { Measuring radiation levels by } \\
\text { themselves }\end{array}$ \\
\hline & Others & $\begin{array}{l}\text { Television, radio, } \\
\text { internet } \\
\text { Family and } \\
\text { community members, } \\
\text { friends }\end{array}$ & $\begin{array}{ll}\text { - } & \text { Television, newspapers, } \\
\text { internet } \\
\text { - } & \text { Family and community } \\
\text { - } & \text { members, friends } \\
\text { - } & \text { Municipal governments } \\
& \text { Experts }\end{array}$ & $\begin{array}{ll}- & \text { Family and community } \\
\text { members, friends } \\
\text { - } & \text { Television, newspapers, } \\
\text { internet } \\
\text { - } & \text { Municipal governments } \\
\text { - } & \text { Experts } \\
& \text { Measuring radiation levels by } \\
\text { themselves }\end{array}$ \\
\hline $\begin{array}{l}\text { Common } \\
\text { challenges }\end{array}$ & & 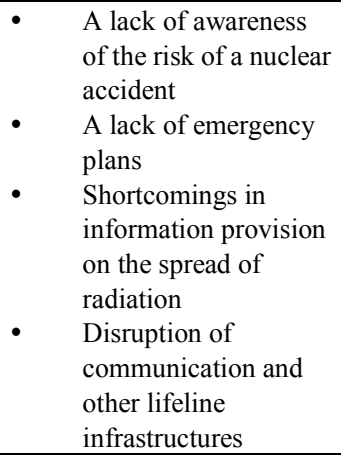 & $\begin{array}{l}\text { - The need for diverse disaster } \\
\text { relief supplies and other } \\
\text { assistance } \\
\text { A lack of familiarity with the } \\
\text { place of evacuation } \\
\text { Increased prevalence of } \\
\text { lifestyle diseases }\end{array}$ & $\begin{array}{ll}\text { - } & \text { Decommissioning of damaged } \\
\text { reactors } \\
\text { Management of a large amount } \\
\text { of radioactive materials with } \\
\text { long half-lives } \\
\text { Disparities in compensation } \\
\text { and emergency relief among } \\
\text { the affected people } \\
\text { - } \quad \text { Differences in radiation risk } \\
\text { perceptions and the ability to } \\
\text { start new lives } \\
\text { Distrust of the government and } \\
\text { TEPCO }\end{array}$ \\
\hline
\end{tabular}

Note: FDNPP = Fukushima Daiich Nuclear Power Plant, TEPCO = Tokyo Electric Power Company, ADR = Alternative Dispute Resolution 


\section{Communication Modalities}

Information sources differed across participants. However, those who were from the evacuation zone generally gained instructions on evacuation through municipal wireless emergency alerts and/or emergency responders, such as firefighters, volunteer fire brigades and municipal government officials. Unlike many other municipalities, the mayor of Kawauchi village ordered full evacuation on March 15 without guidance from the central government [38]. One participant from the village stated that the television news had indicated there was no need to evacuate, and therefore he stayed at home until others in the community told him to do so. Those who belonged to or had a family member who worked for a municipal government or fire brigade at the time of the disaster were able to quickly acquire up-to-date information and evacuate. Study participants from non-evacuation areas mostly relied on information from the television, radio, internet, family and community members and other acquaintances. A participant from Kōriyama city stated that he followed advice from his friend to flee far away in order to avoid radiation that was spreading from FDNPP. The friend had some knowledge of radiation sciences. The participant from Iwaki city himself had a scientific background and evacuated with his family in the first few days after the disaster.

\section{Major Challenges}

Study participants explained to the author that they were completely unaware of the risks of a nuclear accident, and that there was total confusion when it actually happened. Many highlighted that they had been repeatedly told that the nuclear power plant was safe. Some commented that they had had a certain level of concern about a possible nuclear accident, but that they had suppressed these concerns, as victims of the "safety myth". The participant from Date city, for example, stated that she had been naive and ignorant about the risk of a nuclear accident and radiation exposure. She, therefore, focused on dealing with challenges of everyday life caused by the 3.11 disasters, such as the suspension of the water supply, and shortages of fuel oil and food, etc., even when she heard about the accident at FDNPP.

Study participants pointed out that an emergency plan for a nuclear accident had not been developed prior to the disaster in their municipalities. In fact, only municipalities located within a $10-\mathrm{km}$ zone from the nuclear power plant were required to have an emergency plan; and the municipalities and Fukushima prefectural government had not adequately considered a possible major disaster and the resulting large-scale human displacement [6]. The nation's failure in nuclear emergency preparedness led to serious chaos in the initial response, and study participants explained that they had received little instruction on where to evacuate. Some municipalities where an evacuation order was issued by the government arranged buses for evacuation. Yet most of the study participants evacuated using their own vehicles for various reasons, including a long queue because of the prioritization of households with elderly members, expectant mothers and children. They were still at least informed of a direction in which to evacuate, or sometimes a receiving municipality, such as "to Tamura city" (a comment from a participant from Ōkuma town) and "to Iwaki city" (a comment from a participant from Naraha town), by disaster responders, family members or other community members. But many did not know where exactly emergency shelters had been set up. Such information was obtained through acquaintances or local government officials on the way or when they arrived at the receiving municipality. In contrast, in most cases, voluntary evacuees had to determine the destination for evacuation by themselves. Many of them went to the homes of family members or relatives, other places they knew, or in a direction based on their best guess guided by available information, such as the wind direction and road networks. Regardless of evacuation approach and destination, participants had to visit multiple shelters or accommodation centres in order to find spaces for themselves and their family members. Also, the majority of those who evacuated commented on the challenges of gasoline shortages, blackouts, traffic congestion and road damage caused by the earthquakes and tsunami.

In addition, there was an evident shortcoming in information provision on the spread of radioactive materials and the level of contamination. Evacuees from Namie town, for example, remarked that a lack of information especially data from the System for Prediction of Environmental Emergency Dose Information (SPEEDI) which predicts the diffusion of radioactive substances - led them to host displaced people from other municipalities at locations with high radiation levels, and to evacuate unknowingly in the same direction as the spread of radioactive materials from FDNPP. A non-evacuee from Kōriyama city where the radiation level heightened after the disaster also expressed his frustration and said:

The nation failed to protect its people and property. The nuclear accident took place on the day after the Great East Japan Earthquake, and there was temporary suspension of water supply (approximately for 5 days), although we could have electricity. Therefore, Self-Defense Force members brought water with water-supply trucks. We, like residents of other municipalities in Fukushima prefecture, foolishly stood in a line for 3-4 hours outside to get water. I do not know how much radiation we were exposed to during that time.

Additionally, many participants emphasized difficulties in reaching family members and friends to confirm their safety, primarily because of telephone line interruptions for a few days subsequent to the 3.11 disasters. After the recovery of the telecommunication services, it was still arduous for them to figure out the safety of their friends and others unless these people had mobile telephones and the participants knew their contact numbers. As a result, a dependence on personal or community networks developed. The participant from Iwaki 
city was a teacher of a technical high school, and the school utilized its information and communications technology system to inquire after students' safety as soon as electrical power was restored. Contrary to the school in Iwaki city, a participant from Tomioka town, which was severely damaged by ground-shaking and tsunami, noted that schoolteachers were unable to bring contact information of students from the schools and had to reach out to students one by one using their networks.

\subsection{During Evacuation}

\section{Main Concerns and Information Needs}

After relocating to emergency shelters and confirming the safely of family members and others, people's interests swiftly moved onto the availability and receipt of relief supplies, as well as detailed information about the status of the accident at FDNPP and their places of origin to assess the possibility of returning home.

The participant who temporarily evacuated from Kōriyama city returned after learning that no additional explosions had occurred at the FDNPP reactors since March 15 , and ensuring that key infrastructure had recovered and shops reopened in the city. For the other evacuees from the evacuation zone, however, the information made them recognize that the situation was much worse than they had hoped. An evacuee from Ōkuma town commented:

We could watch television and read newspapers (at an emergency shelter). Besides, there were people who went to Ōkuma and took pictures. They showed us the pictures on computers. [...] From the pictures. I learned how much the town had changed (after the 3.11 disasters). It was heartbreaking and made me realize more strongly that I would not be able to go back to Ōkuma.

After realizing that the evacuation would extend for a long period of time, people more eagerly gathered information about relief supplies and the evacuation centres, such as the locations of grocery shops and medical facilities. The majority of study participants first thought that they would be able to return home within a few days or at least within a week, because of their lack of knowledge about nuclear emergencies, the short time that they had before the evacuation, and the government's initial announcement that the evacuation was "only for precaution's sake". They had brought very few belongings from their homes. Moreover, in many cases, people were unfamiliar with the areas where they sought refuge.

After details on the accident at FDNPP were revealed and basic daily needs were being met at places of evacuation, more attention was given to radiation and its health risks; schools for children, including a special school for children with disabilities; temporary housing for evacuees; compensation from TEPCO and the national government; and other available assistance and social services for disaster sufferers. Most evacuee participants in this study had to move from one place to another 4-6 times until they could finally settle in temporary housing or a rent-free apartment prepared for evacuees.

\section{Communication Modalities}

Those who stayed in emergency shelters and temporary housing units tended to seek information through mass media; family members, trusted community members and friends; noticeboards at the sites, and; people from municipal governments of both their place of origin and their place of evacuation, as well as from TEPCO. For those who temporarily stayed in hotels or other types of public or private accommodation, they also asked the management of these facilities. Once municipal governments (re-)started disseminating periodical publications and tablet computers in order to distribute locally specific information, many people also made use of those materials and tools. In contrast, most participants from non-evacuation areas said that they had to actively seek information, using mass media, including the internet, or by asking family and community members, friends, as well as the respective municipal government.

Regardless of whether they were from the evacuation zone or not, those who had a high level of concern about radiation also attended academic meetings and seminars, and directly communicated with experts. As for the mass media, many people relied on information from local television programs and local newspapers. Evacuees from Tomioka town started their own local radio program to provide information useful for daily living, to promote events which enabled dispersed Tomioka people to interact with each other, and to disseminate announcements from the municipal government.

\section{Major Challenges}

Major challenges during evacuation included the shortage of a variety of basic life necessities because of the sudden displacement and the ban issued by the national government on returning to homes located in the evacuation zone. They had to obtain everything anew, and seek any services that they needed. A public health nurse from Naraha town added that some evacuees failed to bring regular medications for chronic illnesses and prescription records. Furthermore, lifestyle changes due to evacuation significantly increased the prevalence of certain illnesses, such as hypertension and diabetes, among the affected [39]. Consequently, public health nurses had to promptly identify such people and liaise with nearby medical facilities.

\subsection{At Present}

\section{Main Concerns and Information Needs}

Study participants provided diverse opinions when the author asked about their current concerns and related information needs. In particular, those who were from the evacuation zone expressed a range of concerns over such issues as radiation, financial matters, housing, hometown 
recovery, fragmented communities, elderly care and child education; whereas participants from non-evacuation areas primarily discussed radiation and health risks. The voluntary evacuee focused on housing, financial matters and resettlement in the place of evacuation.

There was an evident need for precise radiation data directly related with people's daily lives. Participants perceived multiple radiation risks in Fukushima prefecture, involving the decommissioning of the damaged reactors at FDNPP; contaminated soil and other materials gathered through the decontamination process; and radiation exposure in everyday life through air, water, food and soil. People's concerns also related to the runoff of radioactive substances from the vast contaminated forest areas due to storms and heavy rainfall. The current guideline calls for decontamination to be performed in forest areas that are within 20-m proximity of dwellings or agricultural sites [40].

Financial matters were also critical. Although social support will be continued for families living in poverty, the national government will gradually terminate compensation payments along with the lifting of evacuation orders. Other monetary support, such as highway toll exemptions, will also be cut off. Several study participants said that they had filed Alternative Dispute Resolution (ADR) cases with the Dispute Reconciliation Committee for Nuclear Damage Compensation, which was established in response to the nuclear disaster, requesting an increase in compensation. They showed agitation and complained about the lengthy process. One person stated that he and his family had not been able to receive certain compensation payments because they had filed an ADR. They had been using their savings, but it had been difficult for them to get by. Several participants told the author that they were considering taking further action and suing TEPCO and/or the national government, because ADR committee proposals regarding solutions for settlement would not be legally binding.

Employment opportunities and financial security were other common concerns among the participants. The areas affected by the nuclear disaster were previously used by the agriculture, fishery, forestry, livestock and dairy industries. Despite rebounding markets in a few categories [3], market prices are likely to continue to be depressed for many years to come, due to the issue of "harmful rumors" toward products from Fukushima, although the vast majority of the products are within stringent safety limits for radiation $[41,42]$. Furthermore, participants complained about notable mismatches between available jobs and job seekers. For instance, many jobs related to reconstruction, decontamination and the decommissioning of FDNPP opened after the disaster. However, these jobs do not match the skills and knowledge of the unemployed, and the jobs are not permanent [43,44]. Also, these occupations can accelerate the separation of households, requiring breadwinners, in most cases men, to return to the disaster-affected area or neighboring municipalities even if the rest of their family members wish to remain displaced elsewhere.
Housing was a major issue for most of the interviewed evacuees. Many participants' houses in their places of origin were already damaged by earthquakes. They have been further damaged by rain, rodents and insects during the long absence of their inhabitants since the disaster. In addition, one participant commented that the doors of her house had become covered with vines, which made it difficult even to enter the house. Many premises and farming fields have also been ruined by wild animals, such as boars. Some were seeking compensation and trying to find available carpenters for home repairs, demolition or rebuilding of houses. There was a serious shortage of carpenters and a long waiting list to hire them.

In addition, several participants commented on the difficulties related with moving from a temporary housing unit to a public housing unit. Currently Fukushima prefecture is building new public housing units, both for those affected by the earthquake and tsunami and for those affected by the nuclear disaster. An interview participant, however, said that little assistance was given when people move to a public housing unit. According to her, evacuees are expected to become "independent" and be able to handle moving-related matters by themselves. Yet, elderly evacuees often need assistance and information on issues such as approximate costs, choosing moving companies, and finding shops to buy necessities. At the same time, the voluntary evacuee who participated in this study underscored that voluntary evacuees were becoming more and more neglected in this disaster relief scheme. Under current plans, the provision of temporary housing for voluntary evacuees is due to be discontinued after March 2017. However, voluntary evacuees, including those whose hometowns have reopened after decontamination work, do not qualify for the majority of the new subsidized public housing units for evacuees.

The final key concern among study participants was related to their completely changed hometowns. Participants were strongly attached to their hometowns, however, they were skeptical about the possibility for their hometowns to return to how they used to be. They commented that it would take years until the radiation went down to the pre-disaster level and the municipalities complete infrastructure reconstruction. In addition, they noted that not many people would return, and therefore their hometowns would be too quiet and too dark at night. They described that the people who would wish to return were generally senior citizens, and they were afraid to return to declining places where the residents were mostly retired and elderly. In fact, approximately $40 \%$ of Kawauchi returnees are over 65 years old. The population loss has caused a severe reduction of tax revenues, while the costs of nuclear disaster management are ballooning $[45,46]$. At the moment, some of their hometowns accommodate many workers engaged in decontamination work in the neighboring areas and the decommissioning at FDNPP. But their stay is only temporary. Moreover, participants worry about the safety of these neighborhoods because of the sudden and large inflows 
of newcomers. They expressed deep sadness about their damaged community relationships. They were in need of regular updates regarding the status of infrastructure reconstruction, including medical services and social assistance for the elderly; neighborhood safety; opportunities for people to interact with each other and address community maintenance or rebuilding; and their hometown's vision for the future to attract young people, including their plans for new industries and job creation, as well as reopening or building schools and other facilities for children.

\section{Communication Modalities}

Under these circumstances, to seek information most informants relied on family members, trusted community members, friends, publications from municipal governments and TEPCO, as well as local television programs, newspapers and radio. For information on radiation and community rebuilding, some participants continued using the internet and seeking inputs from experts through academic seminars. A few participants from the evacuation zone stated that they also used tablet computers provided by their respective municipal government, while others only used their devices for other purposes. A participant emphasized that tablet computers were difficult to use, especially for older residents, and therefore he kept it in a drawer.

Regarding radiation data, several participants, including returnees of Kawauchi village and those who briefly visited their hometowns, measured air dose rates and the levels of radioactive substances in food products by themselves, with support from experts, in order to ensure their safety.

\section{Major Challenges}

Participants' concerns often stemmed from multiple issues that emerged in the disaster recovery process. TEPCO, for example, has been facing major challenges concerning the removal of melted nuclear fuel debris and the management of rapidly increasing amounts of contaminated water. The company admitted that there had so far been little success in their attempts to halt groundwater flow into the damaged reactors and to prevent contaminated water from leaking into the earth and ocean by creating "frozen soil walls". As of summer 2016, one percent of the underground wall was still unfrozen, and consequently there was no notable reduction in the overall amount of the groundwater flows. The company is planning to cover unfrozen parts of the walls with cement, but the effectiveness of this countermeasure is unknown [47,48]. A participant who used to run a small retail business in Namie town stated:

The biggest risk is that it will take over 40 years for the decommissioning of the nuclear power plant. Namie town (where his dwelling and shop was located) is not more than $10 \mathrm{~km}$ away from the plant. Accordingly, we may have to evacuate again if any incident happens during the course of the decommissioning. Many of us are hesitant to return until the safety is assured.

In addition, there have been significant delays in the decontamination process due to various problems involving the construction of the interim storage facility and a final disposal site, as well as radioactive waste management. Uncertainty about when and to where the massive and growing amount of radioactive waste will be moved for disposal is aggravating people's anxieties over radiation exposure and its health effects. As of February 2016, the total amount of soil and other debris from decontamination reached 11 million cubic meters; of which over $95 \%$ was from Fukushima prefecture. And it is expected that ultimately there will be double the current total of contaminated waste from Fukushima alone [49]. In September 2015, territorial rain hit the eastern part of Japan and swept away bags containing contaminated materials from some temporary storage sites in Fukushima and neighboring prefectures, although no major release of radioactive substances was identified $[50,51]$. The incident stoked people's concerns over safety.

The breakdown of community ties, which was raised by participants, was closely related with the multi-faceted social divisions caused by the nuclear disaster. Although the victims all suffered from severe consequences of the disaster, the amount of compensation awarded differs considerably depending on legal status, such as the assigned evacuation zoning. In the case of Naraha town, most of the residents were in the same zone, and awarded similar compensation. However, some municipalities have been divided into multiple evacuation zones. Local community bonds built over many years were bitterly split due to a sense of unfairness that unfolded as a result of this compensation scheme [21]. Another underlying cause of social division is the differences in perceptions of radiation risks and coping behavior. The study participants confirmed previous study findings $[23,24]$ that young parents with small children tended to feel stronger concerns about radiation and wishes to avoid these risks than elderly people. Compared with younger generations, the elderly are more likely to desire to return to their homes. However, they feel unable to voice their wishes, due to concerns over being left alone if their children are reluctant to follow them. A public health nurse from Naraha town said:

Even though they want to go back to Naraha, younger family members don't. In such situation, if they could discuss it openly, they could move forward. But if they don't, the elderly spend days and months agonizing over the issue and can't decide what to do. Eventually they keep their wishes to themselves and follow the decisions of others, conscious of their limited economic power and waning physical strength.

Furthermore, there was another divide between those who were able to reestablish their livelihoods and leave temporary housing, and those who were unable to do so. 
Participants described this as a "second breakdown of community bonds". When leaving a temporary housing unit, people feel uneasy and become hesitant to inform their neighbors.

Lastly, quite a few participants said that they struggled to trust radiation data released by the government. Their disappointment and anger towards the government and TEPCO remained very strong. They had persistent skepticism about the transparency and accountability of the government and TEPCO. They emphasized the importance of mechanisms through which residents can cross-check such data. Returnees of Kawauchi village also stated that self-measurements of radiation data helped reassure them about their safety and reinforced their resolve to return to their village.

\subsection{Information Disparities}

Participants had strong views on information disparities based of their experiences. Summarizing their comments, this study found that information disparities have emerged between (1) residents at temporary housing units and residents staying elsewhere, including apartments rented out by the prefectural governments for evacuees, (2) the elderly and the young, (3) those with frequent social interactions and those without, and (4) residents in Fukushima prefecture and those outside the prefecture.

Almost all participants who did not live in temporary housing units remarked that they had poor access to information about relief aid and other announcements from municipal governments. According to them, relief aid was distributed generally from residents at temporary housing sites, and as a result, others could not receive them or had to wait. Non-temporary housing residents were not even qualified for some donated food and other supplies, even though they had been displaced from the same municipality.

Study participants also repeatedly explained that there were some people who had limited in-house support but needed assistance to obtain, evaluate, select and apply information useful for their daily lives. CSO representatives provided the author with an example, noting that elderly people in particular were at risk of being unable to read or find necessary information from periodicals produced by municipal governments or from local newspapers. Many of these elderly people also have a certain level of vision and hearing problems which can impair their understanding of television news, and in many cases those people also have limited ability to seek and understand information. Quite a few families used to live with two or three generations together in the same residence before the nuclear disaster, and senior members could receive in-house informational support from their relatives. However, a good number of those families decided to live apart for various reasons, such as the small size of the temporary housing units, and the availability of and access to schools for children. Consequently, the number of elderly-only households has increased significantly in Fukushima prefecture after the
3.11 disasters. As of the beginning of 2016, the proportion of elderly residents of public housing for evacuees reached $35 \%$, compared to the prefectural average of $28 \%$ [52]. There is growing concern about such information vulnerability of elderly residents along with the increase in elderly-only households.

Study participants confirmed that women were more likely than men to worry about radiation effects. However, they pointed out that a high level of concern over radiation was not necessary linked with poor access to information; rather, social isolation could be a strong obstacle to information access and utilization. A few participants commented that men who used to engage in society through their work but lost their jobs due to the disaster were especially at risk of social isolation and poor access to important information.

On top on these information disparities, many of the participants who had evacuated to locations outside Fukushima prefecture at some point, and many of those who remained in other prefectures, described a critical lack of availability of information about Fukushima for those outside the prefecture. Their concern is backed up by a decline in coverage of the disaster in the national-level media [19]. As time goes by, attention is rapidly fading away from the Fukushima region. Some study participants felt that they were falling into obscurity, with many unsolved problems which were becoming even more complicated.

\subsection{Study Limitations}

Participants were recruited through the networks of individual partners and CSOs that were involved in disaster recovery activities or radiation monitoring. This non-probability convenience sampling approach limits the findings. In addition, this study was unable to reach certain population segments, such as expectant mothers or parents who had infants at the time of the disaster. The sample size was small. In particular, there was only one participant each from Date city, Iwaki city and Tamura city. The number of participants who were voluntary evacuees and returnees were also much smaller than the number of participants displaced from the official evacuation zone. The selection of participants caused inherent bias in the study data, and prevented the author from developing meaningful inferences beyond the sample and concluding differences between the study groups. A study with a larger, balanced sample from divergent population groups would provide more insights on the topic of this study.

Individual interviews and focus group discussions were carefully conducted with full attention to neutrality and the importance of enabling all participants to freely express their views. However, radiation, for instance, has become a sensitive topic among affected people, with a fear of false criticism that they are ignorant of science, as well as a concern about raising tensions over radiation risks within the community and even with other family members $[23,53]$. There is an inevitable risk that the presence of others in the 
conversations influenced participants' statements in the study.

It is also important to note that the participants' concerns, information needs and communication modalities may change over time, particularly given the constant changes in their environments. For this reason, the findings of the study cannot account for their future perspectives.

In addition, the information needs reported by the participants were not cross-checked with the actual availability of the specific information to which they referred. Some information could have been available but the participants might not have known where to find it. Further study is essential to evaluate these information gaps.

Lastly, the findings on information modalities that the study participants used in their daily lives do not provide evidence of their effectiveness in information communication. A careful empirical study of this is needed. Also, to improve the information environment, it would be beneficial to investigate the association between information needs and the modalities on which people rely to search for this specific information.

\section{Conclusions}

The findings of this study reflect what has been documented in previous studies, and provide further insights into the challenges of information communication in the context of nuclear disasters. The narratives of study participants show that a nuclear disaster causes strong emotional reactions among affected people, including outrage. In the aftermath of the Fukushima disaster, anxiety, anger and frustration became prevalent among those affected. These feelings were related not only to the fear of unfamiliar and long-lasting radiation risks, but also to the problems with the management of the disaster, the complex consequences of the disaster, the long and difficult process of recovery, and associated uncertainty about the future. This study shows the importance of effective information communication starting from the pre-crisis period and continuing throughout the cycle of nuclear disaster management.

The comments from participants also described a shift in people's information needs from during the disaster, when they sought information related to their survival and assuring the safety of family members and other people, to after the disaster, when they sought more diverse information. People's present concerns, nearly 5 years after the disaster, focus on long-term radioactive contamination, difficulties in livelihood restoration, and social divisions that have damaged community ties. This illustrates the importance of a comprehensive understanding of people's information needs, as well as the need for careful radiation monitoring and genuine disaster-recovery dialogues with concerned people. Continuous assessment of people's concerns and information needs is equally important to effectively reflect their needs in the ongoing disaster recovery efforts.

Although many issues remain to be investigated, this study successfully identified the diverse modalities used by individuals and generated valuable findings on vulnerable populations that can suffer from poor access to information and difficulties in using it. Worryingly, disparities in access to information will likely widen because of the growing number of socially-isolated people, such as those in elderly-only households and the unemployed. This suggests that information should be communicated through multiple channels or carefully disseminated through channels frequently used by the target audience with consideration of linking it with available social assistance. It is hoped that this study's findings will contribute to improving the information environment in which affected people are making decisions for their sustainable recovery from the disaster.

The Fukushima disaster should serve as a critical wake-up call both for Japan, which is in the process of restarting reactors at many of its nuclear power plants, and for the many other countries which have nuclear industries. It is vital for these countries to undertake thorough reviews and reforms of their policies and strategies, to ensure better communication of risks related to nuclear facilities, and for effective preparedness for and response to future disasters.

\section{Notes and Acknowledgements}

This study was conducted as a part of the Fukushima Global Communication (FGC) programme, a research initiative of the United Nations University Institute for the Advanced Study of Sustainability during 2013-2016. The programme was funded by the Nuclear Regulation Authority of Japan. The views expressed in this article are those of the author and do not necessarily reflect the views of the United Nations University.

I would like to thank the CSOs and study participants who kindly supported this study and shared their views and experiences.

\section{REFERENCES}

[1] International Atomic Energy Agency. (2013). The International Nuclear and Radiological Event Scale: User's manual, 2008 edition. Available from: http://www-pub.iaea. org/MTCD/Publications/PDF/INES2013web.pdf, accessed July $11,2016$.

[2] International Atomic Energy Agency. (2015). The Fukushima Daiichi accident: Report by the Director General. Available from http://www-pub.iaea.org/MTCD/Publications/PDF/Pub 1710-ReportByTheDG-Web.pdf, accessed July 11, 2016.

[3] Fukushima Prefectural Government. (2016, December 5). The steps for revitalization in Fukushima, the $18^{\text {th }}$ edition (in Japanese). Available from http://www.pref.fukushima.lg.jp/u ploaded/attachment/193689.pdf, accessed December 20, 2016.

[4] Federal Emergency Management Agency, United States of 
America. (2013). Communicating during and after a nuclear power plant incident. Available from http://www.fema.gov/ media-library-data/20130726-1919-25045-1433/communicat ing_during_and_after_npp_incident_june_2013_secure _.pdf, accessed July $1 \overline{1}, 201 \overline{6}$.

[5] Investigation Committee on the Accident at the Fukushima Nuclear Power Stations of Tokyo Electric Power Company. (2012). Final report. Available from http://www.cas.go.jp/jp /seisaku/icanps/eng/final-report.html, accessed July 11, 2016.

[6] National Diet of Japan. (2012). The official report of the Fukushima Nuclear Accident Independent Investigation Commission. Available from http://warp.da.ndl.go.jp/info:nd ljp/pid/3856371/naiic.go.jp/en/report/, accessed July 11, 2016.

[7] Hasegawa, R. (2013). Disaster evacuation from Japan's 2011 tsunami disaster and the Fukushima nuclear accident (Study No. 05/13). IDDRI/SciencesPo.

[8] Ohtsuru, A., Tanigawa, K., Kumagai, A., Niwa, O., Takamura, N., Midorikawa, S., Nollet, K., Yamashita, S., Ohto, H., Chhem, R. K., \& Clarke, M. (2015). Nuclear disasters and health: Lessons learned, challenges, and proposals. Lancet, 386(9992), 489-497.

[9] Shimura, T., Yamaguchi, I., Terada, H., Svendsen, E. R., \& Kunugita, N. (2015). Public health activities for mitigation of radiation exposures and risk communication challenges after the Fukushima nuclear accident. Journal of Radiation Research, 56(3), 422-429.

[10] Reconstruction Agency, Japan. (2016, March). Current status of reconstruction and challenges. Available from http://www.reconstruction.go.jp/english/topics/Progress to date/image/20160307_Current_Status_of Reconstruction_a nd_Challenges_rev1.p̄pdf, accessed July $1 \overline{2}, 2016$.

[11] Fukushima Prefectural Government. (2016, December 19). Weekly update on the damage caused by the 2011 Great East Japan Earthquake and tsunami, the $1673^{\text {rd }}$ report (in Japanese). Available from http://www.pref.fukushima.lg.jp/uploaded/life/244758_5694 65_misc.pdf, accessed December 20, 2016.

[12] Kwansei Gakuin University Institute of Disaster Area Revitalization Regrowth and Governance, Japan Civil Network, \& Save Fukushima Children Lawyers' Network. (2015). Report on evacuation following the Fukushima Daiichi nuclear power plant accident (in Japanese). Jimbunshoin.

[13] Tomoyasu, K., Kimura, R., Mashima, H., \& Kazama, I. (2015). Issues facing voluntary evacuees from the Fukushima Daiichi nuclear power plant accident based on the collection and analysis of cases of voluntary evacuation. Journal of Disaster Research, 10(sp), 755-769.

[14] Mainichi Shimbun. (2016, March 9). 37\% of Fukushima voluntary evacuees are minors: Mainichi survey. Available from http://mainichi.jp/english/articles/20160309/p2a/00m/0 na/007000c, accessed July 12, 2016.

[15] Mainichi Shimbun. (2016, March 20). 5 years since the 3.11 disasters - Series 16: Yükei Tomitsuka Mayor of Tamura City, concerns of compensation disparities, difficulty in community reconstruction, Fukushima (in Japanese). Available from http://mainichi.jp/articles/20160320/ddl/k07/040/161000c, accessed July 12, 2016.
[16] Fukushima Prefectural Government. (2016). Situations of Naraha town (in Japanese). Available from http://www.pref. fukushima.lg.jp/site/portal/26-6.html, accessed November 14, 2016.

[17] Nuclear Emergency Response Headquarters, Prime Minister of Japan and His Cabinet. (2015). Revision of "Accelerating Fukushima's reconstruction from the nuclear disaster" (adopted by Cabinet Decision, June 12, 2015) (in Japanese). Available from http://www.meti.go.jp/earthquake/nuclear/ki nkyu/pdf/2015/0612_02.pdf, accessed July 12, 2016.

[18] Asahi Shimbun. (2016, July 17). Some restricted zones to be lifted near Fukushima nuclear plant. Available from http://www.asahi.com/ajw/articles/AJ201607170022.html, accessed August 17, 2016.

[19] Ito, M. (2015). Information environment surrounding the Fukushima Daiichi nuclear power plant accident and its radiation problem: From a viewpoint of science technology communication (Fukushima Global Communication Programme Working Paper Series No. 10) (in Japanese). United Nations University Institute for the Advanced Study of Sustainability.

[20] Fukushima Prefectural Government. (2016). The 2016 Opinion Survey of Evacuees from Fukushima Prefecture: Summary report (in Japanese). Available from https://www.pref.fukushima.lg.jp/uploaded/attachment/1709 10.pdf, accessed July 12, 2016.

[21] Safecast. (2016). The Safecast report, volume 2. Available fromhttp://www.slideshare.net/safecast/safecast-report-2016 -final01 print, accessed July 12, 2016.

[22] Shineha, R., \& Tanaka, M. (2014). Mind the cap: 3.11 and the information vulnerable. Asia-Pacific Journal, 12(7), 4.

[23] Morioka, R. (2014). Gender difference in the health risk perception of radiation from Fukushima in Japan: The role of hegemonic masculinity. Social Science \& Medicine, 107, 105-112.

[24] Shimizu, N. (2015). Decision making and gender inequity: In the process of "reconstruction" after the Fukushima nuclear accident (Fukushima Global Communication Programme Working Paper Series No. 9) (in Japanese). United Nations University Institute for the Advanced Study of Sustainability.

[25] Intergovernmental Panel on Climate Change. (2012). Managing the risks of extreme events and disasters to advance climate change adaptation: Special report of the Intergovernmental Panel on Climate Change. Cambridge University Press.

[26] International Atomic Energy Agency. (2014). Climate change and nuclear power 2014. Available from http://www-pub.iaea.org/MTCD/Publications/PDF/ccanp201 4web-14869824.pdf, accessed July 12, 2016.

[27] Du, Y., Ding, Y., Li, Z., \& Cao G. (2015). The role of hazard vulnerability assessments in disaster preparedness and prevention in China. Military Medical Research, 2(27). doi. 10.1186/s40779-015-0059-9.

[28] Reynolds, B, \& Seeger, M.W. (2005). Crisis and emergency risk communication as an integral model. Journal of Health Communication, 10, 43-55.

[29] Slovic, P. (1987). Perception of risk. Science, 296(17 April), 280-285. 
[30] Sandman, P.M. (1993). Responding to community outrage: Strategies for effective risk communication. American Industrial Hygiene Association.

[31] Renn, O. (2004). Perception of risks. Geneva Papers on Risk and Insurance, 29(1), 102-114.

[32] Nuclear Emergency Response Headquarters, Prime Minister of Japan and His Cabinet. (2011). Report of the Japanese Government to the IAEA ministerial conference on nuclear safety: The accident at TEPCO's Fukushima nuclear power stations. Available from http://fukushima.grs.de/sites/default /files/NISA-IAEA-Fukushima_2011-06-08.pdf, accessed July 13, 2016.

[33] Ministry of the Environment, Japan. (2012). Briefing on TEPCO's Fukushima Daiichi NPS accident: Decontamination policies and procedures in Japan (Side event at the Fukushima Ministerial Conference on Nuclear Safety, December 16, 2012, Kōriyama) Available from http://josen.env.go.jp/en/documents/pdf/documents_02.pdf, accessed July 13, 2016.

[34] Ministry of the Environment, Japan. (2014). Japan's decontamination efforts and its effects (The Third International Symposium on Decontamination of Radioactive Materials, July 5, 2014, Kōriyama). Available from http://josen.env.go.jp/en/documents/pdf/japan_decontaminat ion_efforts_and its_effects.pdf, accessed July 13, 2016.

[35] Ministry of Economy Trade and Industry, Japan. (2011). Restricted Area, Deliberate Evacuation Area and regions including specific spots recommended for evacuation (As of November 25, 2011). Available from http://www.meti.go.jp/english/earthquake/nuclear/roadmap/p df/evacuation_map_111125.pdf, accessed July 13, 2016.

[36] Fukushima Minpo News. (2012, December 15). Radiation 'hot spots' in Date, Kawauchi removed from alert list. Available from http://minpol.rssing.com/browser.php?indx= 6609431\&item=17, accessed July 13, 2016.

[37] Krueger, R.A., \& Casey, M.A. (2015). Focus groups: A practical guide for applied research, $5^{\text {th }} \mathrm{ed}$. SAGE.

[38] Kawauchi Village Municipal Government. (2014). The Great East Japan Earthquake and Fukushima Daiichi nuclear power plant accident: Report on the experiences of Kawauchi (in Japanese).

[39] Satoh, H., Ohira, T., Hosoya, M., Sakai, A., Watanabe, T., Ohtsuru, A., Kawasaki, Y., Suzuki, H., Takahashi, A., Kobashi, G., Ozasa, K., Yasumura, S., Yamashita, S., Kamiya, K., \& Abe, M. (2015). Evacuation after the Fukushima Daiich nuclear power plant accident is a cause of diabetes: Results from the Fukushima Health Management Survey. Journal of Diabetes Research, 2015, Article ID 627390, 9 pages.

[40] Ministry of the Environment, Japan. (2015, March). FY2014 decontamination report: A compilation of experiences to date on decontamination for the living environment conducted by the Ministry of the Environment (Tentative Translation). Available from http://josen.env.go.jp/en/cooperation/pdf/dec ontamination_report1503 full.pdf, accessed July 14, 2016.

[41] Tone, M., \& Stone, T. (2014). What we can learn about recovery: Lessons from the Fukushima survivors. Nursing \& Health Sciences, 16(1), 52-55.

[42] Bachev, H., \& Ito, F. (2014). Implications of Fukushima nuclear disaster for Japanese agri-food chains. International Journal of Food and Agricultural Economics, 2(1), 95-120.

[43] Zhang, H., Yan, W., Oda, A., \& Zhang, W. (2014). Radiation-driven migration: The case of Minamisoma city, Fukushima, Japan, after the Fukushima nuclear accident. International Journal of Environmental Research and Public Health, 11(9), 9286-9305.

[44] Mainichi Shimbum. (2016, March 7). 5 year after disaster, reactor decommissioning faces troubling shortage of workers. Available from http://mainichi.jp/english/articles/20160307/ p2a/00m/0na/020000c, accessed July 24, 2016.

[45] Mainichi Shimbun. (2016, June 19). Fukushima village reaches out to single-parent families after evacuation order lifted. Available fromhttp://mainichi.jp/english/articles/2016 0619/p2a/00m/0na/004000c, accessed July 25, 2016.

[46] Fukushima Minpo News. (2015, November 2). Tainted cities irate over Tepco's slow compensation payments: Survey. Available from http://www.fukushimaminponews.com/news .html?id=592, accessed July 25, 2016.

[47] Mainichi Shimbun. (2016, June 2). TEPCO to extend soil walls to block water leakages at Fukushima plant. Available from http://mainichi.jp/english/articles/20160602/p2a/00m/0 na/011000c, accessed July 14, 2016.

[48] Asahi Shimbun. (2016, August 19). Panel: TEPCO's 'ice wall' failing at Fukushima nuclear plant. Available from http://www.asahi.com/ajw/articles/AJ201608190060.html, accessed August 27, 2016.

[49] Asahi Shimbun. (2016, March 11). Progressing decontamination and increasing contaminated waste: Only one municipality has accepted a final disposal facility (in Japanese).

[50] Japan Times. (2015, September 12). Flooding swept away radiation cleanup bags in Fukushima. Available from http://www.japantimes.co.jp/news/2015/09/12/national/flood ing-swept-away-radiation-cleanup-bags-in-fukushima/\#.V4d LmP196Uk, accessed July 14, 2016.

[51] Ministry of the Environment, Japan. (2015). Measures for washed-away contaminated soil and other materials due to torrential rains in Kantō and Tōhoku areas in September 2015 (in Japanese). Available from https://www.env.go.jp/jishin/rmp/conf/16/mat06.pdf, accessed July 14, 2016.

[52] Mainichi Shimbun. (2016, March 4). 11 residents at reconstruction housing died unnoticed in 1 year. Available from http://mainichi.jp/english/articles/20160304/p2a/00m/0 na/015000c, accessed July 25, 2016.

[53] Hirakawa, H., \& Shirabe, M. (2015). Rhetorical marginalization of science and democracy: Politics in risk discourse on radioactive risks in Japan. In Y. Fujigaki (Ed.), Lessons from Fukushima: Japanese case studies on science, technology and society (pp. 57-86). Springer. 